\title{
Music perception in cochlear implant users: an event-related potential study
}

\author{
Stefan Koelsch $^{\mathrm{a}, \mathrm{b}, *}$, Matthias Wittfoth ${ }^{\mathrm{c}}$, Angelika Wolf ${ }^{\mathrm{a}}$, Joachim Müller ${ }^{\mathrm{d}}$, Anja Hahne \\ ${ }^{\mathrm{a}}$ Max Planck Institute of Cognitive Neuroscience, Stephanstrasse 1a, 04103 Leipzig, Germany \\ ${ }^{\mathrm{b}}$ Harvard Medical School, Boston, MA, USA \\ ${ }^{\mathrm{c}}$ University of Heidelberg, Heidelberg, Germany \\ ${ }^{\mathrm{d}}$ University of Würzburg, Würzburg, Germany
}

Accepted 28 November 2003

\begin{abstract}
Objective: Compare the processing of music-syntactic irregularities and physical oddballs between cochlear implant (CI) users and matched controls.

Methods: Musical chord sequences were presented, some of which contained functionally irregular chords, or a chord with an instrumental timbre that deviated from the standard timbre.

Results: In both controls and CI users, functionally irregular chords elicited early (around $200 \mathrm{~ms}$ ) and late (around $500 \mathrm{~ms}$ ) negative electric brain responses (early right anterior negativity,ERAN and N5). Amplitudes of effects depended on the degree of music-syntactic irregularity in both groups; effects elicited in CI users were distinctly smaller than in controls. Physically deviant chords elicited a timbremismatch negativity (MMN) and a P3 in both groups, again with smaller amplitudes in CI users.

Conclusions: ERAN and N5 (as well as timbre-MMN and P3), can be elicited in CI users. Although amplitudes of effects were considerably smaller in the CI group, the presence of MMN and ERAN indicates that neural mechanisms of both physical and musicsyntactic irregularity-detection were active in this group.
\end{abstract}

(C) 2004 International Federation of Clinical Neurophysiology. Published by Elsevier Ireland Ltd. All rights reserved.

Keywords: Cochlear implant; Auditory processing; Music; Electroencephalogram; Early right anterior negativity; Mismatch negativity; N5

\section{Introduction}

Electrical stimulation of the auditory nerve by a cochlear implant (CI) can restore hearing in profound bilateral deafness of sensorineural origin. Implants allow adults to recover speech comprehension and children to acquire language. In pre-lingually deaf adults, implants restore auditory alerting functions, but rarely speech comprehension.

Compared to an intact natural cochlea, CI systems still provide only reduced auditory information, and there is demand for implant systems that better meet the hearing needs. While many CI users enjoy success regarding speech

\footnotetext{
Note: Examples of the stimuli are available at http://www. stefan-koelsch.de.

* Corresponding author. Tel.: +49-341-994-0121; fax: +49-341-9940113.

E-mail address: mail@stefan-koelsch.de (S. Koelsch).
}

understanding, most of them are still frustrated by their inability to accurately hear music. Moreover, the ability for an accurate differentiation of pitch information is crucial for the understanding and production of a tone language (e.g. Cantonese, or Mandarin), in which changes of the fundamental frequency pattern within a phonemic segment determine the lexical meaning. CI users in countries with tone languages do not seem to derive the same benefit as individuals who speak non-tonal languages (Fu et al., 1998; Cruz and Zeng, 2001), and the pattern of (Cantonese) tone perception development of children with CIs does not seem to follow that of normal children (Lee et al., 2002).

Up to now, numerous studies investigated speech recognition in CI users, but only few reports on how musical sounds are perceived through a CI have been published (Eddington et al., 1978; Pijl and Schwarz, 1995a, b; McDermott and McKay, 1997; Fujita and Ito, 1999; Gfeller et al., 1997, 1998; Gfeller and Lansing, 1991, 1992; 
see also Beynon et al., 2002). With regard to typical music listening experiences, implant recipients enjoy music less post-implantation than prior to hearing loss.

The major focus of the present study was to investigate electric brain potentials in CI users while they listen to music, and compare these potentials to those elicited in normal (control) listeners. Recent studies investigating music perception with a very similar experimental design (Maess et al., 2001; Koelsch et al., 2000, 2002a,b), showed that within a musical context, music-syntactically irregular chords elicit early and late event-related brain potentials (ERPs). These ERPs were denoted as early right anterior negativity (ERAN, maximal around $200 \mathrm{~ms}$ after the onset of an irregular chord) and N5 (maximal around $500 \mathrm{~ms}$ ). In these studies, as in the present study, sequences consisting of 5 in-key chords were composed in a way that progressing chords built up a musical context (top row of Fig. 1). Such a musical context buildup correlates with the buildup of expectancies in listeners for harmonically regular chords to follow (Krumhansl and Kessler, 1982; Bharucha and Krumhansl, 1983). Infrequently, an irregular chord function (Neapolitan sixth chord) was presented at either the third or the fifth position of a chord sequence (see also Fig. 1). The irregular chord functions violate the regularities of (major-minor tonal) musical structure. The ERAN is taken to reflect the processing of such musicstructural, or music-syntactic, violations (Koelsch et al., 2000; Maess et al., 2001). The ERAN is usually followed
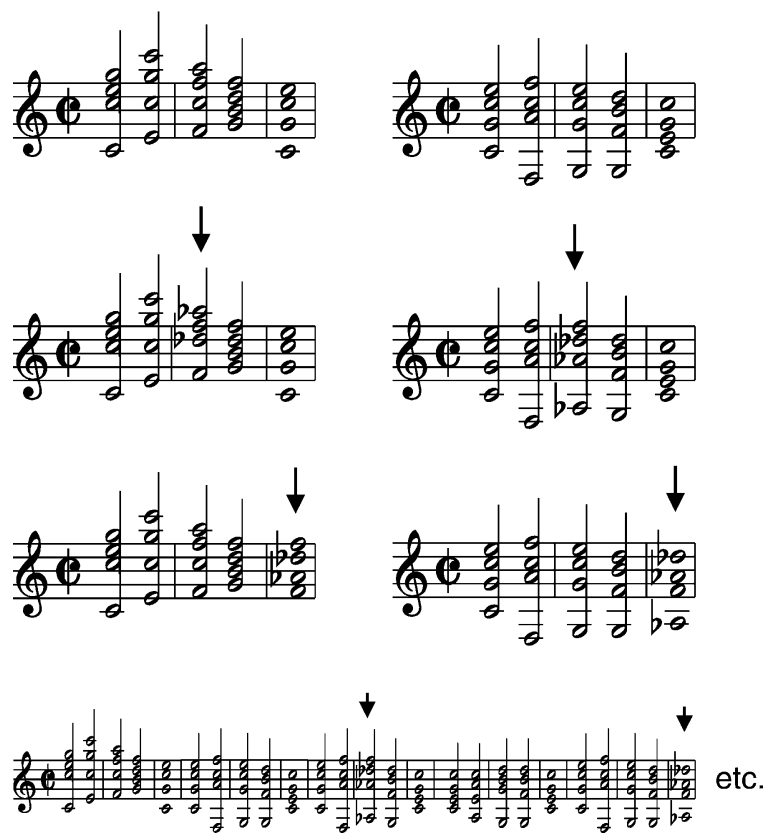

Fig. 1. Examples of chord sequences: sequences exclusively consisting of in-key chords (top row); sequences containing a Neapolitan chord at the third position (second row), and sequences containing a Neapolitan at the fifth position (third row), Neapolitan chords are indicated by arrows. During the experiment, chord sequences were presented in direct succession (bottom row). by a later negativity (the N5) which is maximal around 500-550 ms. The N5 is taken to reflect processes of harmonic integration (Koelsch et al., 2000).

Note that Neapolitans at the fifth position were, from a music-theoretical view, more irregular than at the third position: a Neapolitan instead of a tonic at the end of a sequence is highly irregular, whereas a Neapolitan instead of a subdominant at the third position is only moderately irregular (a Neapolitan is classically used as a subdominantvariation and pre-dominant chord; for more detailed descriptions see Maess et al., 2001; Koelsch et al., 2000, 2002a,b). That is, the degree of music-syntactic irregularity was varied, and a corresponding variation of ERP amplitudes is taken to reflect music-syntactic processing (for details see Koelsch et al., 2001).

The ERAN shares some important features with the mismatch negativity (MMN, e.g. Schröger, 1998), most obviously scalp distribution, and sensitivity for auditory events that do not match with a previously presented group of events (for more detailed descriptions see Koelsch et al., 2000, 2001, 2002a). However, note that it has previously been shown that effects of Neapolitans are not due to a mere physical 'oddball' characteristic, but that the ERAN elicited by irregular chord functions mainly reflects processing of musical structure. Thus, the ERAN may not be regarded as a physical (frequency) MMN (Koelsch et al., 2001).

It is an open question if ERAN and N5 can be elicited in CI users. To investigate this issue, the experimental paradigm described above was presented to postlingually deafened CI users and age- as well as gender-matched controls. To test if the same groups of subjects also show an MMN-response to physically deviant auditory stimuli, infrequently a chord of a sequence was played with a timbre that deviated from the standard piano timbre (see Section 2). Based on previous studies investigating other MMN-types in CI users (Kraus et al., 1995; Ponton et al., 2000; Wable et al., 2000), a timbreMMN was expected to be elicited in CI users.

\section{Methods}

\subsection{Subjects}

Twelve CI users (mean age 51.8 years, range 34-77, 9 women) and 12 age- and gender-matched normal hearing subjects (mean age 49.8 years, range $34-62$, 9 women) participated in the experiment. All CI users were postlingually deafened. Eleven participants used the Combi 40 + implant (MED-EL) with the CIS strategy (Wilson et al., 1991), one participant used the Nucleus 24 implant (cochlear) with the ACE strategy (Table 1).

\subsection{Stimuli}

The musical stimulus was virtually identical to 4 previous studies (Maess et al., 2001; Koelsch et al., 2000, 
Table 1

Clinical profiles of implant patients

\begin{tabular}{|c|c|c|c|c|c|c|c|c|}
\hline \multirow[t]{2}{*}{ Patient } & \multirow[t]{2}{*}{ Sex } & \multirow{2}{*}{$\begin{array}{l}\text { Age } \\
\text { (years) }\end{array}$} & \multirow[t]{2}{*}{ Etiology } & \multicolumn{2}{|c|}{ Duration of } & \multirow[t]{2}{*}{ CI-type } & \multirow[t]{2}{*}{ Strategy } & \multirow[t]{2}{*}{ Side of implant } \\
\hline & & & & Deafness & Rehab & & & \\
\hline I & M & 52 & Ab SNHL & 2 & 1 & Combi $40+$ & CIS & $\mathrm{L}$ \\
\hline II & $\mathrm{F}$ & 45 & Hereditary & 25 & 2.8 & Combi $40+$ & CIS & $\mathrm{L}$ \\
\hline III & $\mathrm{F}$ & 48 & Hereditary & 2 & 1.2 & Nucleus & $\mathrm{ACE}$ & $\mathrm{L}$ \\
\hline IV & M & 63 & Otosclerosis & 33 & 6 & Combi $40+$ & CIS & Bilateral \\
\hline V & $\mathrm{F}$ & 42 & Meningitis & 5 & 4.2 & Combi $40+$ & CIS & $\mathrm{R}$ \\
\hline VI & $\mathrm{F}$ & 52 & Unknown origin & 5 & 2.3 & Combi $40+$ & CIS & $\mathrm{R}$ \\
\hline VII & M & 63 & Otoslerosis & 33 & 3.9 & Combi $40+$ & CIS & $\mathrm{R}$ \\
\hline VIII & $\mathrm{F}$ & 44 & Otoslerosis & 11 & 1.2 & Combi $40+$ & CIS & $\mathrm{L}$ \\
\hline IX & $\mathrm{F}$ & 34 & Ab SNHL & 5 & 0.6 & Combi $40+$ & CIS & $\mathrm{R}$ \\
\hline $\mathrm{X}$ & $\mathrm{F}$ & 77 & M. meniére & 10 & 6.9 & Combi $40+$ & CIS & $\mathrm{R}$ \\
\hline XI & $\mathrm{F}$ & 52 & Meningitis & 4 & 1.3 & Combi $40+$ & CIS & $\mathrm{L}$ \\
\hline XII & $\mathrm{F}$ & 50 & Unknown origin & 7 & 2.1 & Combi $40+$ & CIS & $\mathrm{L}$ \\
\hline
\end{tabular}

Ab, abrupt deafness; SNHL, sensorineural hearing loss; and rehab, rehabilitation.

2002a, 2003). Two-hundred-sixty chord sequences (each sequence consisting of 5 chords) were played under computerized control via MIDI on a Roland JV-2080 synthesizer with a piano sound. One-hundred-seventy-two different chord sequences were composed: The first chord was always the tonic of the following chord sequence. Chords at the second position were tonic, mediant, submediant, subdominant, dominant to the dominant, secondary dominant to mediant, secondary dominant to submediant, secondary dominant to supertonic. Chords at the third position: subdominant, dominant, dominant 6-4 chord, Neapolitan sixth chord; at the fourth position: dominant seventh chord. Chords at the fifth position: tonic or Neapolitan sixth chord.

Neapolitan chords at the third position never followed a secondary dominant. Neapolitan chords at the fifth position never followed a Neapolitan chord at the third position. Both Neapolitan chords occurred with a probability of $25 \%$ (resulting in the presentation of 65 Neapolitans at the third, and 65 at the fifth position). Presentation time of chords one to 4 was $600 \mathrm{~ms}$, the fifth chord was presented for $1200 \mathrm{~ms}$. In $15 \%$ of the sequences an in-key chord from position two to 5 was played by an instrument other than piano (e.g. Trumpet, organ), resulting in a total of 40 chords played on deviant instruments. All chords were on average physically identical with respect to their loudness. There was no silent period between chords or chord sequences; one chord sequence directly followed the other (bottom of Fig. 1). Sequences were presented via speakers (see also below).

\subsection{Procedure}

Participants were seated in a comfortable chair in an electrically and acoustically shielded room. They were instructed to keep their eyes open and to look at a fixation cross. They were only informed about the deviant instruments, not about the Neapolitan sixth chords or their nature.
An example of a chord sequence played with piano sound and of a chord sequence in which one chord was played by a deviant instrument (organ) was presented to each participant before starting the electroencephalogram (EEG) measurement. For the CI users, loudness was individually adjusted in a way that patients reported that they could comfortably hear the musical stimulus. For the controls, the musical stimulus was presented with a loudness of approximately $60 \mathrm{~dB}$ (all control subjects reported that they comfortably heard the stimulus). Participants were instructed to ignore the harmonies and to count the deviant instruments. Six times during the experimental session the stimulation was briefly paused, and two numbers were presented on the computer screen. Participants were instructed to indicate which of these two numbers corresponded to the number of deviant instruments by pressing one of two response buttons. After such an inquiry, sequences were presented in a tonal key that differed from the tonal key used before the inquiry (preventing the musical stimulus from becoming monotonous).

\subsection{EEG measurements}

The EEG was recorded from 19 scalp sites of the 10-20 system (AESN, Sharbrough, 1991): Fz, F3, F4, F7, F8, FC3, FC4, FT7, FT8, Cz, CP5, CP6, Pz, P3, P4, P7, P8, O1, O2. For CI users, the mastoid electrode contralateral to the implanted side was used as reference electrode. Reference for control subjects was the left mastoid. Sampling rate was $250 \mathrm{~Hz}$ per channel (lowpass $40 \mathrm{~Hz}$ ). Horizontal and vertical electrooculograms were recorded bipolarly. Raw data were filtered off-line using a $0.25-25 \mathrm{~Hz}$ bandpass filter (1001 points, FIR). Subsequently, epochs with artifacts caused by eye- and body movements were rejected based on visual inspection. 


\subsection{Data analysis}

For statistical analysis, electrodes were grouped into regions of interest (ROIs) by computing the mean score of the amplitudes elicited at the electrodes of a ROI (Oken and Chiappa, 1986). For statistical analyzes that included data from the CI group, a frontal ROI was computed comprising the electrodes Fz, F3, F4, FC3, and FC4, and a parietal ROI comprising the electrodes Pz, P3, P4, CP5, and CP6. In order to analyze lateralization of frontal effects in the control group, two frontal ROIs were computed: left (F3, F7, FC3, FT7) and right (F4, F8, FC4, FT8).

Variances of ERPs were analyzed by repeated measures analyzes of variance (ANOVAs). Time windows for statistical analyzes were centered around the maxima of ERP effects. The time windows for the control group correspond to the time windows analyzed in previous studies (Koelsch et al., 2000, 2001, 2002b): 150-250 ms (early time window), and 500-600 ms (late time window). The early time window for the CI users was $200-400 \mathrm{~ms}$, the late time window was the same as for the control group (500-600 ms). After statistical analysis, data were filtered with a $20 \mathrm{~Hz}$ lowpass filter (41 points, FIR) for presentation purposes.

\section{Results}

\subsection{Regular and irregular chords}

ERP waveforms of the chords at the fifth position are shown in Fig. 2. In controls, the irregular (Neapolitan) chords elicited distinct effects: an ERAN was maximal around $180 \mathrm{~ms}$, and strongest over right-anterior electrode leads. The ERAN was followed by a late bilateral negativity with frontal preponderance that had an onset around $400 \mathrm{~ms}$ and was maximal around $500 \mathrm{~ms}$ (the N5). In CI users, irregular chords at the fifth position also elicited early and late effects (ERAN and N5) that were considerably smaller compared to those elicited by the control group (see also Fig. 5). The early negativity had a longer duration in CI users (around 200-400 ms), and early and late effects were less clearly distinctive compared to controls.

ERPs elicited at the third position are shown in Fig. 3. In controls, irregular chords elicited an ERAN and an N5, with a clearly smaller amplitude than at the fifth position. In CI users, neither ERAN nor N5 were elicited by the irregular chords at the third position (see also Fig. 5).

Observations were corroborated by statistical analyzes: a global ANOVA for the frontal ROI with factors chord-type (regular chords, irregular chords), group (CI users, controls), position (third, fifth), and time-window (early, late; see Methods) revealed an effect of chord-type $(F(1,22)=26.99, P<0.0001$, reflecting that the irregular chords elicited significant effects), an interaction between factors chord-type and group $(F(1,22)=23.43$, $P<0.0001$, reflecting that effects had a larger amplitude in controls than in CI users), and an interaction between factors chord-type and position $(F(1,22)=15.45$, $P<0.001$, reflecting that the effects were larger at the fifth than at the third position). Analogous ANOVAs conducted separately for controls and CI users yielded significant interactions of factors chord-type and position for both groups (controls: $P<0.0006$, CI users: $P<0.05$, indicating that the amplitude difference of effects between fifth and third position was significant for both groups). Effects elicited at the fifth position were significant in both groups (controls: $F(1,11)=103.27, \quad P<0.0001$; CI users: $F(1,11)=5.66, P<0.05)$. Separate analyzes for
A controls, 5th position
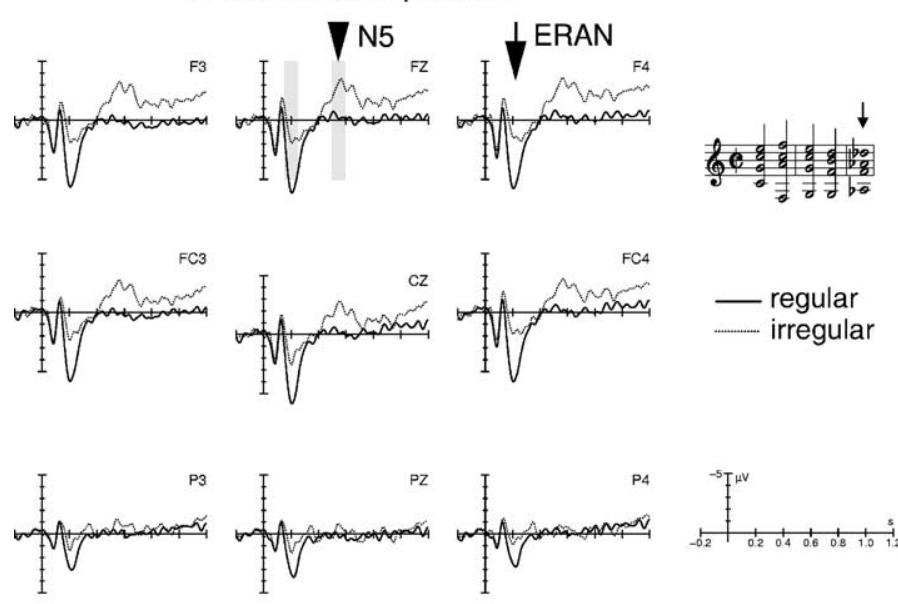

B Cl-users, 5th position
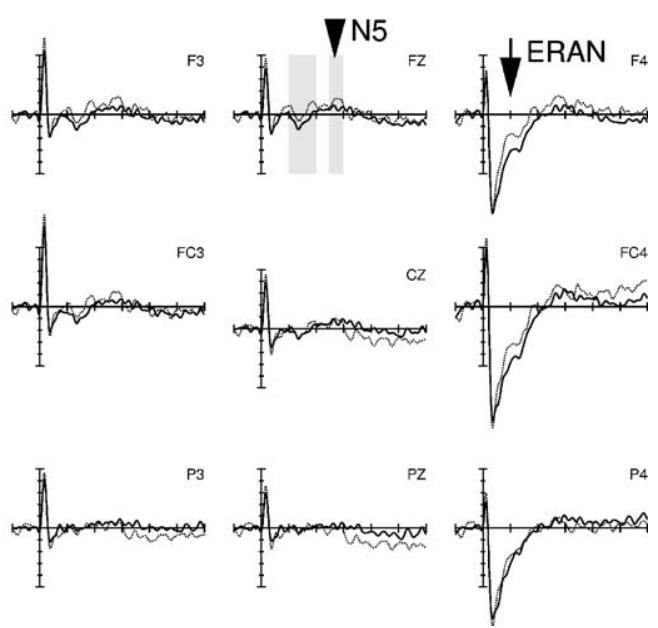

Fig. 2. Grand-average ERP-waveforms elicited by chords at the fifth position, separately for controls (A); and CI users (B). In controls, irregular chords elicited early and late negative effects (ERAN and N5). CI users showed similar effects, although effects had a considerably smaller amplitude. Time windows used for statistical analyzes are indicated by the grey-shaded areas. 
A controls, 3rd position

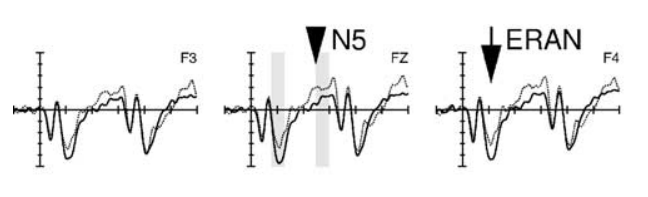

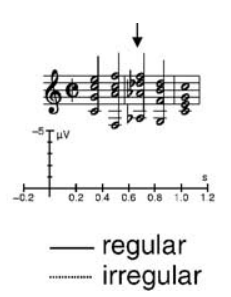

B Cl-users, 3rd position

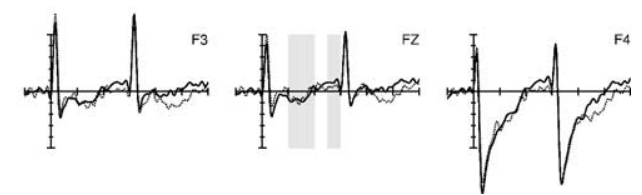

Fig. 3. ERPs elicited at the third position. In controls (A), irregular chords elicited a small ERAN, and a small N5. In CI users (B) the two waveforms virtually did not differ from each other.

the ERAN and the N5 time windows at the fifth position indicated significant effects for both groups (control group: $P<0.001$, CI users: $P<0.05$ in each analysis). At the third position, effects were significant only in the control group (controls: $\quad F(1,11)=13.13, \quad P<0.005$, CI users: $F(1,11)=1.55, P>0.2)$.

To test the lateralization of the ERAN in controls, an ANOVA was computed for the early time window with factors chord-type, position, and hemisphere (left, right frontal ROI, see Section 2). Results revealed an interaction between factors chord-type and hemisphere $(F(1,11)=$ 5.87, $P<0.05$, no 3-way interaction was indicated, as expected). The analogous ANOVA for the late (N5) time window did not reveal an interaction between factors chordtype and hemisphere $(P>0.98$, reflecting that the N5 had a bilateral scalp distribution). Because of the effect of the CI on the ERPs (in most participants implanted unilaterally), no laterality of effects was analyzed in the group of CI users.

\subsection{Deviant instruments}

Behaviorally, the control group achieved $79 \%$ correct responses (range: 66-100\%), whereas the CI group had only $66 \%$ correct responses (range: $33-83 \%$ ), the behavioral difference between groups being significant $(P<0.05$, one-tailed $t$ test $)$.

In both groups, ERP-waves of deviant instruments (compared to chords played with the standard piano sound) elicited a distinct timbre-MMN (Toiviainen et al., 1998; Tervaniemi et al., 1997), probably with additional contributions of an enhanced N1 and an N2b (Fig. 4). The negative effect was followed by a P3 (maximal around $400 \mathrm{~ms}$ over parietal electrode sites). Effects were clearly smaller in CI users than in controls (see also Fig. 5), corresponding to the behavioral data. The early negative effect was observable in all CI users, a correlation between hit rate and amplitude of ERP-effects was not significant, neither for the early negativity, nor for the P3 (probably due to the low number of trials with deviant instruments which led to ERPs with a relatively low signal-to-noise ratio).

An ANOVA with factors instrument (chords played on a piano, chords played on a deviant instrument) and group for the early negative effect (150-250 ms time window, frontal ROI) revealed an effect of instrument $(F(1,22)=44.61$, $P<0.0001)$, and an interaction between the two factors $(F(1,22)=11.63, \quad P<0.003)$. When analyzing both
A controls, deviant instruments

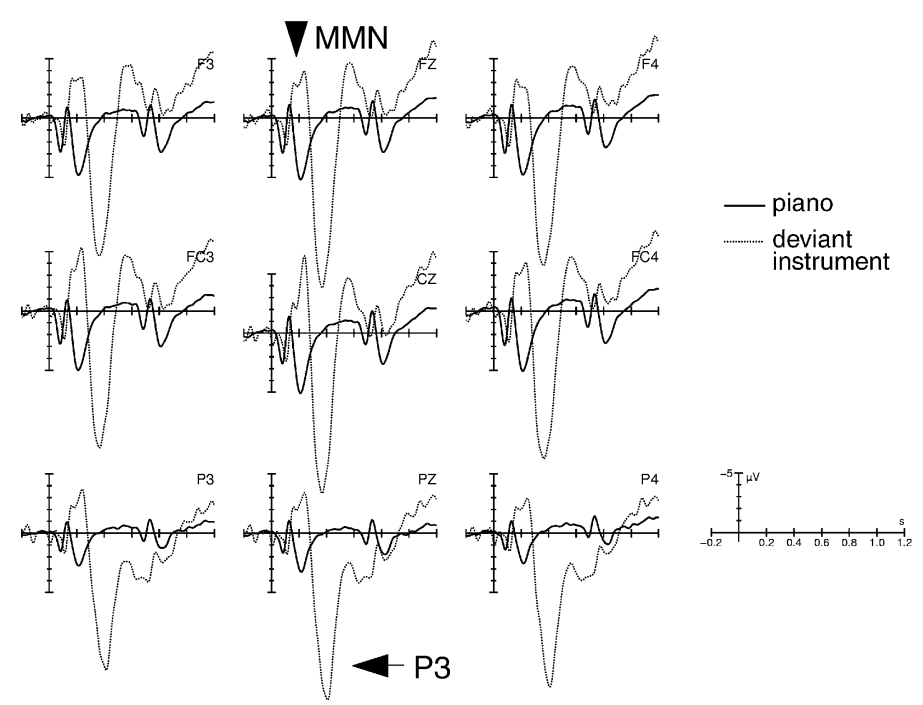

B Cl-users, deviant instruments
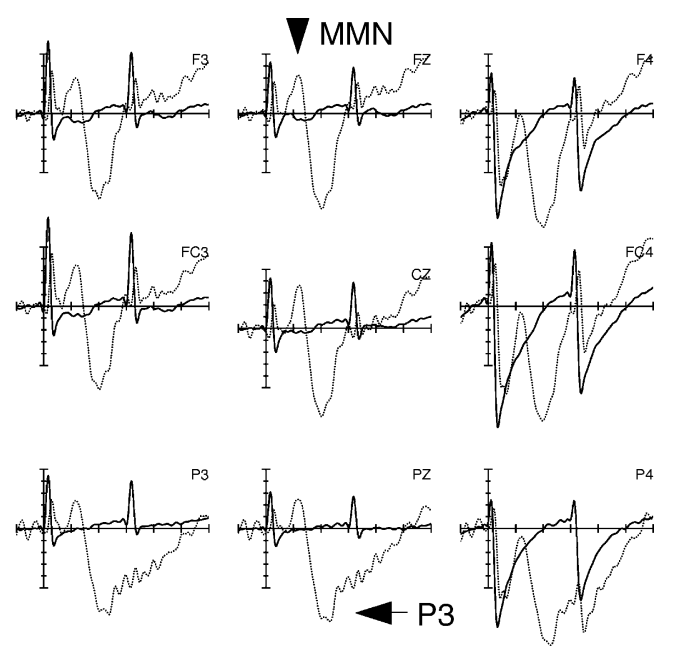

Fig. 4. ERPs elicited by the chords played with deviant instrumental timbre compared to chords played on a piano, separately for controls (A); and CI users (B). In both groups, deviant instruments elicited a timbre-MMN and a P3. Effects had smaller amplitudes when elicited in the CI group. 


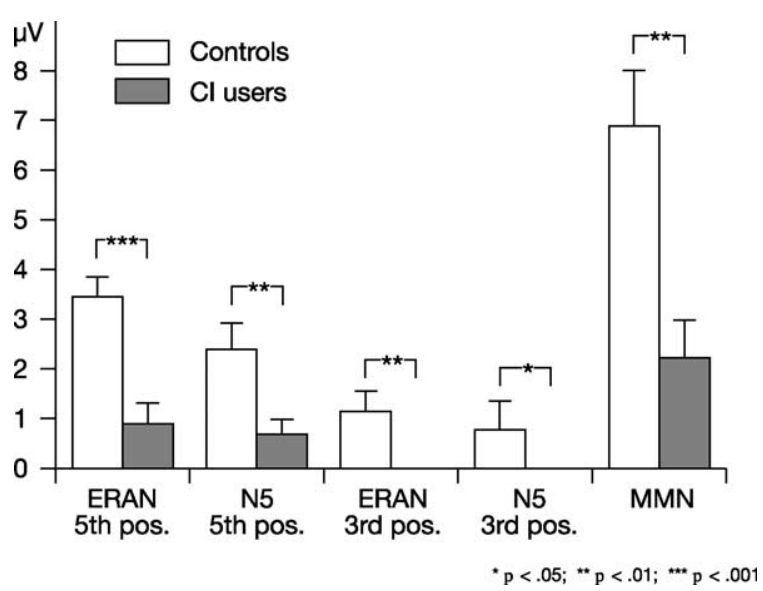

Fig. 5. Mean amplitude values and standard errors of effects (ERAN and N5: regular chords subtracted from irregular chords; MMN: standards subtracted from deviants), calculated for the time-windows and electrodes of interest used in the statistical analysis. Mean amplitudes of all effects differed significantly between controls and CI users. In CI users, irregular chords presented at the third position of the chord sequences neither elicited an ERAN, nor an N5. Note that in both groups amplitudes of effects were considerably larger at the fifth than at the third position of the sequences.

groups separately, a significant effect of instrument was indicated in both groups (controls: $P<0.0001$, CI users: $P<0.02)$. The analogous ANOVA for the $\mathrm{P} 3$ time window (350-450 ms, parietal ROI) indicated an effect of instrument $(F(1,22)=110.67, P<0.0001)$, and an interaction between the two factors $(F(1,22)=4.67, P<0.05)$, effects of instrument were indicated for both groups $(P<0.0001$ in both groups).

\section{Discussion}

In the present experiment, irregular chord functions (Neapolitan sixth chords) elicited early and late negative brain responses (ERAN and N5) in both controls and CI users. The amplitudes of effects were considerably smaller in CI users than in controls. Note that in controls (for whom tests of lateralization of effects could be performed), the ERAN was lateralized, whereas the N5 was bilateral (in accordance with previous studies, e.g. Koelsch et al., 2001). This difference in lateralization indicates that ERAN and N5 reflect separate cognitive processes (and are not merely a single tonic negative effect). The finding that effects were smaller in CI users reflects that the amount of sensory information received through a $\mathrm{CI}$ is smaller compared to an intact natural cochlea. The lower amount of information decreased the saliency of the musical violations, and it has been shown in previous studies, that the amplitudes of ERAN and N5 are dependent on the saliency of musical violations (e.g. Koelsch et al., 2000).

Importantly, amplitudes of effects differed within groups between the two positions of the chord sequences (third and fifth) at which the Neapolitans were presented. That is, in both groups the amplitudes of ERAN and N5 varied according to the degree of music-syntactic irregularity. This variation demonstrates that both groups processed the chords according to the regularities of (major-minor tonal) musical structure (effects related to the processing of a physical deviancy do not differ in amplitude between third and fifth position, Koelsch et al., 2001, see also Section 1). Note that a Neapolitan chord itself is a perfectly common major triad, it is mainly the musical context in which a Neapolitan has a harmonic function that sounds peculiar.

With this respect, the present results suggest that, despite the limited amount of sensory information provided by a CI, postlingually deafened CI users process musical information (as indexed by the ERAN and the N5) with the same neural mechanisms as normal hearing controls (but note that ERP-effects had clearly smaller amplitudes). That is, although many of the CI users investigated reported that they had difficulties in discriminating musical information, and that they are generally frustrated by their inability to accurately hear music, the presence of the ERP-effects observed indicates that brain functions that process musical irregularities were still active.

It seems very likely that a cognitive representation of the major-minor tonal system had been established before the patients lost their hearing, and that this representation is still a basic reference for musical analysis. That is, attempts to improve accuracy of music perception in CI users by modifying their processors can rely on an intact representation of musical regularities in CI users.

It is interesting to note that, according to the present results, fast and fairly automatic processes of musicsyntactic analysis (as indicated by the ERAN) are active in CI users: Fast and automatic processes of syntactic analysis of language, although reminiscent to those of music processing (Maess et al., 2001; Koelsch et al., 2000), were not observed in CI users in a recent study (Hahne et al., 2001). One explanation could be that the musical stimulus was easier to decode than speech, resulting in an ERAN during the processing of music, but not in analogous operations during the processing of language. Another possible explanation is that the music was equally, or even more difficult to decode than speech, but that the fast and automatic processes of structural analysis are regained faster in the musical than in the linguistic domain. This issue remains to be specified.

Chords infrequently played by deviant instruments elicited a timbre-MMN in both CI users and normal-hearing controls. Although the amplitude of the MMN was smaller in CI users than in controls, findings indicate that a timbreMMN can be elicited in CI users. This implicates that the automatic change detection mechanism of the auditory sensory memory was operating, independent of whether the stimulus was processed through a normal cochlea or mediated by a CI (in accordance with results from previous studies investigating the MMN in CI users, see Kraus et al., 1993, 1995; Wable et al., 2000). 
In summary, the present study demonstrates that ERAN, $\mathrm{N} 5$, and timbre-MMN can be evoked in patients with cochlear implants, although with clearly reduced amplitudes compared to normal hearing control subjects. That is, although amplitudes of deviance-related negativities were considerably smaller in the CI group, the presence of these effects indicates that both physical and music-syntactic irregularities were neurally detected by the subjects. The presence of the music-related effects in CI users shows that CI users (still) have a representation of regularities of the major-minor tonal system, even after an extended period of hearing loss. Note that the ERAN reflects mechanisms which process musical information fast and fairly automatically, and that the ERAN was observed in CI users despite the reduced auditory input provided by a CI. Future studies might investigate the development of musical functions in children with a $\mathrm{CI}$.

\section{Acknowledgements}

This research was supported by a grant from the German Research Council (DFG) awarded to A. Hahne (DFG HA 3153/1-1).

\section{References}

Beynon AJ, Snik AFM, van den Broek P. Evaluation of cochlear implant benefit with auditory cortical evoked potentials. Int J Audiol 2002;41: 429-35.

Bharucha J, Krumhansl C. The representation of harmonic structure in music: hierarchies of stability as a function of context. Cognition 1983; 13:63-102.

Cruz R, Zeng FG. Music perception in cochlear implant users. Speech processors for auditory prothesis. NIH Neural prothesis program quarterly progress report 2001;9:27-8.

Eddington D, Dobelle W, Brackmann D, Mladejovsky M, Parkin J. Place and periodicity pitch by stimulation of multiple scala tympani electrodes in deaf volunteers. Trans Am Soc Artif Intern Organs 1978;24:1-5.

Fu QJ, Zeng FG, Shannon RV, Soli SD. Importance of tonal envelope cues in Chinese speech recognition. J Acoust Soc Am 1998;104:505-10.

Fujita S, Ito J. Ability of nucleus cochlear implantees to recognize music. Ann Otol Rhinol Laryngol 1999;108:634-40.

Gfeller K, Lansing C. Melodic, rhythmic, and timbral perception of adult cochlear implant users. J Speech Hear Res 1991;34:916-20.

Gfeller K, Lansing C. Musical perception of cochlear implant users as measured by the primary measures of music audiation: an item analysis. J Music Ther 1992;29:18-39.

Gfeller K, Woodworth G, Robin D, Witt S, DeBus B. Perception of rhythmic and sequential patterns by normally hearing adults and adult cochlear implant users. Ear Hear 1997;18:252-60.

Gfeller K, Knutson J, Woodworth G, Witt S, DeBus B. Timbral recognition and appraisal by adult cochlear implant users and normal-hearing adults. J Am Acad Audiol 1998;9:1-19.
Hahne A, Wolf A, Kiefer J, Mueller J. Prozesse des Satzverstehens bei Cochlea-Implant-Trägern: Hirnelektrische Evidenz für ein Primat der Bedeutungsverarbeitung. Z Audiol 2001;4(Suppl.):27-9.

Koelsch S, Gunter T, Friederici AD, Schröger E. Brain indices of music processing: 'non-musicians' are musical. J Cogn Neurosci 2000;12: $520-41$.

Koelsch S, Gunter T, Schröger E, Tervaniemi M, Sammler D, Friederici AD. Differentiating ERAN and MMN: an ERP-study. NeuroReport 2001;12:1385-9.

Koelsch S, Schmidt B, Kansok J. Influences of musical expertise on the ERAN: an ERP-study. Psychophysiology 2002a;39:657-63.

Koelsch S, Schröger E, Gunter T. Music matters: preattentive musicality of the human brain. Psychophysiology 2002b;39:1-11.

Koelsch S, Grossmann T, Gunter T, Hahne A, Friederici A. Children processing music: electric brain responses reveal musical competence and gender differences. J Cogn Neurosci 2003;15:683-93.

Kraus N, Micco A, Koch D, McGee T, Carrell T, Sharma A, Wiet R, Weingarten $\mathrm{C}$. The mismatch negativity cortical evoked potential elicited by speech in cochlear-implant users. Hear Res 1993;65: $118-24$.

Kraus N, McGee T, Carrell T, Sharma A. Neurophysiologic bases of speech discrimination. Ear Hear 1995;16:19-37.

Krumhansl C, Kessler E. Tracing the dynamic changes in perceived tonal organization in a spatial representation of musical keys. Psychol Rev 1982;89:334-68.

Lee K, van Hasselt C, Chiu S, Cheung D. Cantonese tone perception ability of cochlear implant children in comparison with normal-hearing children. Int J Pediatr Otorhinolaryngol 2002;63:137-47.

Maess B, Koelsch S, Gunter T, Friederici AD. 'Musical syntax' is processed in the area of Broca: an MEG-study. Nat Neurosci 2001;4: 540-5.

McDermott H, McKay C. Musical pitch perception with electrical stimulation of the cochlea. J Acoust Soc Am 1997;101:1622-31.

Oken B, Chiappa K. Statistical issues concerning computerized analysis of brainwave topography. Annu Neurol 1986;19:493-4.

Pijl S, Schwarz D. Melody recognition and musical interval perception by deaf subjects stimulated with electrical pulse trains through single cochlear electrodes. J Acoust Soc Am 1995a;98:886-95.

Pijl S, Schwarz D. Intonation of musical intervals by deaf subjects stimulated with single bipolar cochlear implant electrodes. Hear Res 1995b;89:203-11.

Ponton CW, Eggermont JJ, Don M, Waring MD, Kwong B, Cunningham J, Trautwein P. Maturation of the mismatch negativity: effects of profound deafness and cochlear implant use. Audiol Neurootol 2000; 5:167-85.

Schröger E. Measurement and Interpretation of the mismatch negativity (MMN). Behav Res Methods Instrum Comput 1998;30:131-45.

Sharbrough F. American Electroencephalographic Society Guidelines for standard electrode position nomenclature. J Clin Neurophysiol 1991;8: 200-2.

Tervaniemi M, Winkler I, Näätänen R. Pre-attentive categorization of sounds by timbre as revealed by event-related potentials. NeuroReport 1997;8:2571-4

Toiviainen P, Tervaniemi M, Louhivuori J, Saher M, Huotilainen M, Näätänen R. Timbre similarity: convergence of neural, behavioral, and computational approaches. Music Percept 1998;16:223-41.

Wable J, van den Abbeele T, Gallego S, Frachet B. Mismatch negativity: a tool for the assessment of stimuli discrimination in cochlear implant subjects. Clin Neurophysiol 2000;111:743-51.

Wilson B, Finley C, Lawson D, Wolford R, Eddington D, Rabinowitz W. Better speech recognition with cochlear implants. Nature 1991;352: 236-8. 